"This document is the Accepted Manuscript version of a Published Work that appeared in final form in the International Journal of Therapy and Rehabilitation, copyright (C MA Healthcare, after peer review and technical editing by the publisher. To access the final edited and published work, see https://www.magonlinelibrary.com/doi/10.12968/ijtr.2018.25.5.223."

\title{
Physiotherapists' experiences of respiratory compromise in patients with Parkinson's disease: A qualitative study
}

\section{Nikki Walker, Jane Cross}

\section{$\underline{\text { Abstract }}$}

Background/Aims: To explore the experiences and perceptions of physiotherapists involved in the care of people with Parkinson's disease and respiratory compromise.

Methods: This exploratory qualitative study recruited four physiotherapists who participated in a focus group and completed reflective diaries over a 3-month period. Experiences were explored using Interpretative Phenomenological Analysis.

Findings: The study highlights three key themes: application of professional knowledge, application of clinical decision making and challenges to application of care.

Conclusions: The results demonstrate sensitive awareness in caring for a dependent and vulnerable population whose key motor signs, compounded by ageing are perceived as influencing the presentation of respiratory compromise. There are descriptions of a reactive response to illness, alongside reflections on the challenges faced when asserting autonomy and recognising where the role of physiotherapy fits within the multidisciplinary team. Sputum clearance is perceived as being a key aspect of this role, although there is uncertainty with regard to the effectiveness and appropriateness of treatment options. Multiple perceived challenges to care provision are highlighted, with key concerns surrounding clinician and patient 
knowledge levels, maintenance of patient mobility, person centred care and clarity in the direction of care.

Key words: Experiences; Hospital; Physiotherapy; Parkinson's disease; Respiratory

\section{Introduction}

Parkinson's disease is a progressive neurodegenerative condition characterised and clinically defined by "bradykinesia plus rigidity and rest tremor or both" (Postuma et al. 2016: 546). Affecting approximately $2 \%$ of the population over 65 (Leibson et al. 2006a), there is no known curative therapy (Bramley and Eatough, 2005). The major impact of the disease is on physical and social functioning alongside psychological well-being (Reese, 2007), with potential for Parkinson's disease to have significant impact on health service funding and resource use (Dowding et al. 2006) as the cost of care is more than double that of people without Parkinson's disease (Leibson et al. 2006b).

Respiratory dysfunction may be present in the early stages of Parkinson's disease but becomes clinically apparent later (Pal et al. 2007; Sabate et al. 1996); with pneumonia being the main cause of non-elective admission to hospital (Low et al. 2015) and death (Pinter et al. 2015). Theories of respiratory dysfunction are well documented yet management seldom considered in the same detail as motor manifestations (Schrag et al. 2002).

Physiotherapy has been part of the supportive management of respiratory compromise in neuro-degenerative conditions for many years (Jones et al. 2012). However other than 
National Institute for Health and Care Excellence (NICE) guidance for the use of non-invasive ventilation within Motor Neurone disease (NICE, 2016a) there is little guidance for physiotherapists for the respiratory treatment of neuro-degenerative conditions. The NICE guidelines for Parkinson's disease (2017) and Tomlinson and colleagues (2012) systematic review do not highlight a role for physiotherapy in management of respiratory complications although the European Physiotherapy Guidelines for Parkinson's disease recognise respiratory impairments as "important to physiotherapy care" (Keus et al. 2014: 32) and give suggested treatment ideas. Furthermore Ashburn et al. (2004) suggests physiotherapy can minimise secondary complications of the disease process.

Four studies explore the management of respiratory compromise specifically in people with Parkinson's disease, yet the potential role of the physiotherapist is not discussed (Koseoglu et al. 1997; Inzelberg et al. 2005; Pitts et al. 2009; Troche et al. 2010). Clinical trials have not directly considered a relationship between Physiotherapy and respiratory function in Parkinson's disease. Research is therefore required to explore the experiences of physiotherapists who work with this patient group so as to better understand our professional role and support an efficient and effective response to the needs of the person with Parkinson's disease.

\section{Methods}

This research foregrounds people's experiences as worthy of investigation, not as universal truth - but as a construction of a chosen populations perceptions, in that setting, at a specific time, leading to multiple constructed realities (Lincoln and Guba, 1985). Thus to capture the information leading to a better understanding of the experiences of physiotherapist's, 
qualitative research methods are used (Wiart and Burwash, 2007). This paper draws on a hermeneutic approach called Interpretative Phenomenological Analysis (IPA) to gain personal insight of physiotherapists working in the context of respiratory care for people with Parkinson's disease, to facilitate description and interpretation of experiences (Hanson, 2006).

In November 2014, a purposive sampling method was used to recruit participants from a National Health Service (NHS) Trust in the East of England who were considered by peers as 'experts' working within inpatient neurology and elderly care teams. Four participants were approached who met the inclusion criteria, each having a minimum of 10 years clinical experience and all who gave informed consent and completed the study. Each participated in a 90-minute focus group, conducted in a quiet non-clinical room, audio recorded and facilitated using a semi structured topic guide by NW. The questions used a recommended framework (Eliot and Associates, 2005) which encouraged openness alongside a flexible opportunity to probe further. Enquiry was made as to the participant's beliefs, experiences and perceptions relating to the patient group. Throughout the focus group, the Researcher said little except to clarify a point or to encourage the participants to explore an aspect further (Webb, 2003) so as to minimise the role of the Researcher as a physiotherapist. Field notes were recorded immediately after the session. Participants were provided with a reflective diary for three months. Instructions were kept open and participants were asked to record experiences and perceptions related to the area of research. A total of 14 entries were recorded. Anonymity and confidentiality have been assured throughout the data collection and presentation process. The study concluded in July 2015.

\section{Ethical approval}


The study was approved by the University of East Anglia's Faculty of Medicine and Health Sciences Research Ethics Committee.

\section{$\underline{\text { Analysis }}$}

Focus group data were transcribed verbatim. The focus group and diary entries were analysed individually but in the same manner; primary analysis was completed by NW and refinement and development in discussion with JC. The researcher's field notes were also incorporated into transcripts.

Three types of exploratory commenting were used; descriptive, linguistic and conceptual (Smith et al. 2009). They were applied in a line-by-line approach, documented on the transcript. Attention to the hermeneutic circle, "moving back and forth between an overall interpretation and an interpretation of significant parts" (Bradbury-Jones et al. 2010: 27), encouraged a dynamic relationship with the data and interpretation from multiple perspectives (Smith et al. 2009). Refinement led to identification of three superordinate themes and eleven subthemes formed through a "cohesive interpretation" of experiences across focus group and diary entries (John et al. 2009: 262).

In terms of professional practice, these superordinate themes link to the application of condition specific knowledge, the application of clinical decision making and also consider what challenges there are to application of care. (Fig 1)

$\underline{\text { Results and discussion }}$ 


\section{Application of professional knowledge}

\section{$\underline{\text { Recognising Respiratory compromise }}$}

Participants described a wide range of symptoms observed in the hospitalised patient with Parkinsons's disease, from increasing and altered respiratory rates to increased secretions. While the symptoms are synonymous with the presentation of respiratory compromise in most neuro-degenerative conditions (Jones et al. 2012), the language used specifically depicts the distress that these participants feel the patient with Parkinson's disease experiences.

'Their respiratory rate increases because they're struggling (pause) a bit more.' (P002; focus group)

Hesitation and reference to "a bit more" appears to highlight an uncomfortable awareness that people with Parkinson's disease struggle even before the presence of acute illness. Furthermore, it is proposed that apparent fluctuation in physical presentation, which may lead to such anticipation being difficult, is caused by medication:

‘He never really regained much mobility. That was complicated by his dyskinesias and medication changes so some days he was flailing and other days he was absolutely set solid' (P001; focus group)

The statement mirrors the experiences described by people living with Parkinson's disease who feel their body is in a "state of flux and unrest" which leads to a feeling of "powerlessness" in the hands of medication required to control the body (Bramley and Eatough, 2005: 227-228).

\section{Perceptions on causal factors of respiratory compromise}


The literature suggests respiratory compromise is likely the result of several inter-related components including dysphagia (Kalf et al 2012), an impaired cough function (Ebihara et al. 2003; Fontana and Lavorini, 2006), weak respiratory muscles (Berry et al. 1996) and changes in muscle tone (Sabate et al. 1996). The participants in this study perceive that a reduction in expiratory muscle power has particular influence:

'cough likely weak, possibly even ineffective secondary to ability to generate power from diaphragm / ribcage recoil / abdominals.' (P001; diary entry)

'their muscles aren't as well developed, not eating as well so they have less physical reserve to help clear their chests (pause) making the outcome worse, when they do get an infection' (P002; focus group)

Participants also perceive that individuals struggle due to changes in muscle tone and suggest that this contributes to postural challenges and in turn reduced mobility; both thought to be influential in development of respiratory compromise (Sathyaprabha et al. 2005).

'increased rigidity esp. LL's [lower limbs] poor stand between 2, dragging R [right] LL' (P001; diary entry)

'medication not on time that can increase the stiffness could lead to an acute deterioration.' (P001; focus group)

An initiative promoted across the United Kingdom called 'Get It on Time,' places multifaceted responsibility on those who support medication delivery and education in hospitals (Parkinson's UK, 2015). People living with Parkinson's disease reflect the importance of initiatives like this by suggesting that without medications "I would have no life" (Bramley and Eatough, 2005: 228). The participants in this study demonstrate awareness of this critical 
dependence on others for getting medication on time and suggest it specifically helps to prevent changes in muscle tone.

The influence of a poor swallow on development of aspiration pneumonia is reflected on by these participants:

'reduced swallow, so they've got an increased chance of aspirating.' (P002; focus group)

The word "chance" suggests unpredictability whilst also indicating hope that swallow may improve and reduce the likelihood of aspiration. Positioning is linked to increased safety of swallow and one participant suggests that there is a dependency on health care professionals to help reduce the risk of aspiration:

'is it going far too quick? Have they got the right consistency? Have they given the pacing time that it takes these patients to, to swallow and be ready for the next one especially if they have got already a bit of increased work of breathing 'cause if you're breathless and someone's still trying to keep feeding it in, it's just gonna [go down the wrong way] so education [is required]' (P004; focus group)

The depersonalising image of "still trying to keep feeding it in" suggests concern for a loss of person-centred care within the hospital setting and subtle reference is made to the potential role of education in this. However achieving person-centred care in hospitals may also be problematic due to demand for shorter lengths of stay (Clisset et al. 2013; Francis, 2013). 
All participants linked older age and reduced mobility with the development of respiratory compromise. Their experience of treating younger, more mobile people with Parkinson's disease informed this. Description of the compounding influence of multiple infections highlights the perceived vulnerability of the older person with Parkinson's disease.

'Each time they have an insult to their chest, I don't think they fully recover the sort of physical qualities of their chest and then they, I think they're at higher risk of deterioration, sort of, again the next time because they just haven't got that reserve to, to manage.' (P003; focus group)

Participant 003's use of the word "insult" suggests the perceived force with which disease attacks the older patient and echoes the experience reported by an individual with Parkinson's disease who feels she "cannot win the battle with her body" (Bramley and Eatough, 2005, p.230).

Two participants suggest advances in healthcare may cause individual patient suffering to be unduly prolonged:

'because we're keeping them going so now we're getting people who are dying, living a lot longer but in a more disabled condition' (P002; focus group) 'we are keeping people (pause) alive for so much longer, we over medicalise them a lot' (P003; focus group)

A despondency of tone reflects concern for the discomfort of individual patients, perceived to be living "longer" on account of medical progress. Increasing age and associated disability is recognised as contributing to greater pressures on hospitals and thereby is hugely significant in terms of impact on available resources (Department of Health and Social Care, 2001). 
The publication of 'Making our health and care systems fit for an ageing population,' (The King's Fund, 2014), outlines key messages for coordinating a healthcare service around the needs of ageing individuals with increasingly complex needs. However, these participants appear to question the application of these messages to practice.

\section{Nature of decline}

The prevalence of falls in people with Parkinson's disease is high (Keus, 2014). These participants suggest that respiratory decline may occur following a fall, due to an associated loss of mobility.

'presenting with first fall but long lie [lying on the floor a long time]...normally living alone, unable to stand, [and at] risk of developing hypostatic pneumonia' (P001; focus group)

They also reflect on how it can be difficult to stabilise a patient's presentation once they arrive in hospital. In particular, participant 002 reflects on observing a sudden and rapid deterioration, alongside a feeling of embarrassment for being 'caught out' by symptoms of respiratory compromise.

'spiralling down' ( P002; focus group)

'caught out with things.....a sputum plug which came out of nowhere' ( P002; focus group)

This presents a reactive approach to care and questions this participant's knowledge and understanding of Parkinson's disease. Furthermore, these observations raise doubt as to whether the current organisational structure of healthcare in the UK is fully able to meet the 
needs of this ageing population, not least within hospitals but also through actively challenging the success of current initiatives that are focused on admission avoidance (The Kings Fund, 2010; NHS Employers, 2014).

\section{Application of clinical decision-making}

\section{Goals of treatment}

A reactive approach is a concern highlighted further by data that suggests the participants feel responsibility for fixing the problem. This in turn suggests a perception and / or hope, that chest infections are reversible:

'usually by that time if they have got a chest infection, I'm too busy trying to fix it so the education's not as important, then, you've got to try and get them over initial (pause) problem.' (P002; focus group)

The tone here is sharp and direct; reflecting frustration that appropriate information was apparently not imparted to the patient earlier. Yet Williamson et al. (2008: 586) suggests professionals may not be 'completely open about the complications' of Parkinson's disease, and this negatively impacts on an individual's ability to cope with the disease progression. It is suggested that being proactive can help to 'avoid the costly and escalating medical and pharmaceutical treatments that accompany having the disease' (Griffiths, 2014 p.20), whereas adopting a more reactive response to illness could lead to increased pressure on resources, inevitably threatening quality of care provision. 
Participants suggested that if patients received education from a physiotherapist earlier, this may reduce need later; but hospital is not the appropriate place to receive such education:

'it's not always the right place to do...the right time or here, the right setting to really do some of that education because it takes time, it takes none of those interruptions' (P001; focus group)

The participants suggest that it is Primary Care health care professionals who should fulfil this role.

Participants expressed concern that a hospital admission robs individuals of their independence. Compounding this are concerns that an often expeditious discharge means a patient has not made sufficient recovery to withstand inevitable recurrent chest infections:

'so focused on getting over the acute medical [issue] and getting them out at a level that they [can] function at. Who is really getting them truly back to that previous exercise tolerance? [Who is] getting them as good as possible to make [them] as robust [as possible] before the next insult happens' (P001; focus group)

Guidance and campaigns exist that aim to improve the experience of care for people using NHS services and encourage support for patients to engage in their own care needs when in hospital (NICE, 2012; Riley, 2017). Participant P001 highlights the possible failure to use such guidance and question whether our treatment goals fail to realise the full physical effects of illness contributing to functional decline, compared with other populations.

Both physiotherapists and patients are presented as wanting to improve mobility, however the underlying motivation is different. The physiotherapist understands the relationship 
between movement and lung function, whilst the patient simply wants to be able to walk. Understanding why participants may feel unable to explain the secondary benefits warrants exploration. Larsson et al. (2010: 218) highlight the value of a "therapeutic alliance" to establish agreement in goal setting. Whilst hospital may or may not be the appropriate place to form this alliance there is a need for HEALTH CARE PROFESSIONAL's to prioritise care needs and identify patient choice, perhaps in the clinic setting (Van der Marck et al. 2009).

\section{Experience of techniques that aid sputum clearance}

Supporting sputum clearance is discussed in detail both in focus group and diary data. A variety of techniques are discussed: mobility; manual techniques; nasopharyngeal (NP) suction; intermittent positive pressure breathing (IPPB) and mechanical insufflation exsufflation (MI-E); however there is uncertainty regarding the effectiveness of these due to weak evidence for the management of respiratory compromise in Parkinson's disease (Jones et al. 2012).

Encouraging mobility, is emphasised by all participants and they theorise that this is an uncomplicated way to increase lung function, stimulate coughing, and assist sputum clearance.

Participants advocate manual techniques emphasising relaxation during treatment: 
'You can get a little bit of relaxation sometimes with gentle percussion to then be able to do something a bit more, a bit more active.' (P001; focus group)

Participant P004 reflects positively on manual techniques highlighting the value of integrating skills:

'If the secretions are loose, then with that and chest vibes sometimes they cough'

The participants discuss the role of NP suction in detail. They are concerned that it's an unpleasant technique:

'It's not something that I enter into lightly ..... it's I always think it should always be a be a last resort because of what its potential complications could be.' (P001; focus group)

This use of "last resort" emphasises how uncomfortable it may be for both a patient and physiotherapist. In their diary, participant 001 makes reference to the decision to employ NP suction in the "best interest" of the patient. Justifying the decision represents a source of conflict for the physiotherapist between patient autonomy and treatment intended to support sputum clearance which is however uncomfortable. Conversely, when successful its efficacy justifies why it is used:

'It's great when you get a good result because they can feel the difference...feel the benefit straight away.' (P001; focus group)

NP suction is a difficult technique to master, which may explain some of the concerns: 
'It's frustrating when that's what needs to happen and you can't either pass it or its curling and its feel like it's there in the right place but you're still not getting it, and then that's absolutely infuriating'(P001; focus group)

Literature supports this unpleasantness where its use in neuromuscular conditions is considered distressing and invasive (Anderson et al, 2005). Hence, there are questions whether its use "reflects the right of patients to determine what happens to their own bodies;" (Department of Health, 2009: 9) and highlights the value that advanced care planning may have for a patient group who may be unable to consent to treatment at the point it may be necessary (NICE, 2017).

IPPB and MI-E in sputum clearance was a key discussion in the focus group, although not supported by the diary data; so their role in day-to-day practice is unclear. Three of the four participants had experience in using a cough assist machine with patients with Parkinson's disease.

The group suggested that MI-E may feel more claustrophobic and invasive than IPPB, a concern for participants worried about the experience and possible discomfort for the patient. Such concerns affect decisions regarding treatments, with resignation to using NP suction as the perceived most effective treatment option.

\section{Professional autonomy}


The literature portrays conflict between the desire for professional independence and the desire for effective team working. There is a consensus that "to be truly independent is idealistic, impossible and undesirable" because "this impinges on the autonomy of others" (Wilkinson, 1997: 704). The participants in this study reflect similar conflict in which they identify strongly with the concept of professional autonomy yet feel restricted by limitations that the doctors place on their physiotherapy practice. In turn, we see a resentful reaction to the perceived hierarchy within multidisciplinary teams (MDT) alongside an element of insecurity:

'We are autonomous practitioners...if a complaint comes in or something happens, it's me that's got to stand and say why I did what I did and I would not say 'the consultant told me to try NP suction and it wasn't right for the patient, they didn't tolerate it and I shouldn't have done it'. It has to be what I'm happy to do' (P001; focus group)

'...willing to treat recurrent aspirations but placing limitations on physio intervention. As physios we have to be guided by medical decisions but what we can offer + success of our interventions will depend on medical decisions.' (P003; diary entry) 'This is what really needs to happen ....and we've discussed it with the medical team.' (P001; focus group)

In the case of these participants, it may be that reduced confidence in clinical reasoning contributes to the threat to autonomy, perhaps reinforcing the importance of professionals communicating in order to support professional growth (Wilkinson, 1997). 


\section{Challenges to application of care}

Variance in Knowledge levels within the multidisciplinary team

A range of specialist and non-specialist multidisciplinary healthcare professionals are responsible for the care provision of those with Parkinson's disease within hospitals (Jones and Hindle, 2011). Participants expressed particular concern with the knowledge of unqualified nursing staff:

'most of the care being done by the nurses or HCAs (health care assistants), you know, HCAs are feeding our patients, positioning our patients, helping mobilise our patients, they doing a lot a lot of our nursing care, and their understanding of Parkinson's disease will probably be very limited, and that's no fault from them, that's the band they are and that's the job that they do, but they are the people who are doing all of our care throughout the twenty four hours of the day for these patients that and that's where some of the education is [needed]around is the wider MDT [multidisciplinary team].' (P001; focus group)

The repetition of the word "our" appears to emphasise the degree to which a physiotherapist may feel ownership, or responsibility for the treatment of a patient. Tension is caused by the understanding that - without specific training - the actions of well-intentioned HCA's could inadvertently compromise or undermine the aims of the physiotherapists' treatment leading participants to be unanimous in their call for staff education.

In 2009, the All-Party Parliamentary Group on Parkinson's highlighted poor understanding amongst HEALTH CARE PROFESSIONAL's, however six years later these participants still appear to be raising significant and legitimate concerns regarding the understanding of 
Parkinson's disease amongst health care professionals. This also appears to increase pressure on physiotherapy services, as highlighted in an example of when a physiotherapist may be called to a patient unnecessarily by staff whose understanding of Parkinson's disease is inadequate:

'Staff on the ward might sometimes panic and go "ooh they sound really chesty, [call for the] chest physio" and it's sometimes more it's about education.' (P001; focus group)

The importance of access to professionals with a good understanding of Parkinson's disease is supported by Jones and Hindle (2011: 87) who state that "managing the interface between symptom control and drug side effects can be complex and challenging, particularly in the acutely ill patient." This study's participants present themselves as well placed to share professional knowledge and support the development of others to improve outcomes for patients.

\section{Wider understanding of the physiotherapist's role}

There is a suggestion that, in this patient group, there is not a consistent understanding of the physiotherapist's role. For example, prescribing a drug employed in end of life care to dry up secretions (NICE, 2016b), whilst also asking physiotherapists to clear secretions is felt to be counterproductive:

'I think sometimes also there's a lack of understanding of what we can achieve...the classic is that the doctors will (pause) give patients doses of hyoscine and ask for chest 
physio...there's a lack of understanding of the impact that that (hyoscine) will have on our role' (P003; focus group)

The literature suggests that in order to address this, education needs to begin at undergraduate level (Lee and Sheppard, 1998).

\section{Person Centred Care}

The concept of person-centred care encompasses a vision of "patients as equal partners in planning, developing and accessing care most appropriate for their needs" (The Health Foundation, 2015) and is advocated in guidance for the care of those with Parkinson's disease (NICE, 2017). Although one participant highlights awareness of patient individuality, it is notable in focus group and diary data that there is little reference to patient involvement in decision-making.

'You couldn't make a flow-chart saying if this do this...it depends on the individual, the time, everything, so many variables' (P002; focus group)

Despite consideration as to how treatment might feel to the patient, discussion surrounding use of NP suction presents how this as an afterthought to the litigatory implications of a treatment technique going wrong:

'.....especially when it's around the NP suction, worst case scenario, what could happen, what it involves, how it possibly feels for the patient' (P001; focus group) 'I can't see how I'm going to do him any harm trying either so let's try and exhaust all options' (P001; focus group)

The attempt to "exhaust all options" conveys the desire to feel that everything has been done to meet the needs of the patient, yet ironically highlights how little choice the patient has in 
a situation of rapidly declining health and how vulnerable personal autonomy can be within healthcare contexts (Entwistle et al. 2010).

Counter to this is patient involvement in decision making with regard to eating and drinking: '(patient has) chosen to eat and drink at own risk despite identified as significant aspiration risk' (P003; diary entry)

The patient's decision to eat and drink could be viewed positively regarding personal choice; however, the participant appears to condemn this. Beauchamp and Childress (2009) cited in Entwistle et al. (2010) highlight the importance of autonomous decisions being made when an individual has good understanding and is free from controlling influences. In the context of rapidly declining health it should be questioned whether a patient can fully understand the "menu of options" presented to them (Entwistle et al 2010: 742).

Instead, it has been suggested that timing of patient education should be gradual over the course of the illness to assist adjustment to disease progression (Williamson et al. 2008). This may go some way to enabling patient informed choice (Entwistle et al. 2010).

\section{Maintaining Patient Mobility on the Ward between therapy sessions}

It has been suggested that reduced mobility allows respiratory symptoms to manifest (Sathyaprabha et al. 2005). The participants in this study support the importance of mobility in care for the inpatient with Parkinson's disease: 
'teaching, training nursing staff will help and mobility's the best thing for this patient because you know sitting in bed, uh, is not going to do any good to them.' (P004; focus group)

There are also some concerns that nursing staff are not always helping patients to maintain their mobility whilst in hospital:

'...completely nursed in bed ...usually outcomes [are] not fantastic.' (P002; focus group)

Reference to being "nursed" in bed, makes it clear that they do not equate this with good care. Literature on hospitalised older adults supports this; "patients are frequently placed on bedrest upon hospital admission and remain there, often without valid medical reasons" producing "an important risk factor for adverse hospital outcomes" (Brown et al. 2004: 1267). Participants implicate the greater organisational structure of hospitals and limited staffing as contributing to the risk of patient decline:

'they (nurses) don't encourage patient to sit out, because they are at risk of falls maybe not enough staffing, they may need one to one staffing so they leave them in bed for their safety" (P004; focus group)

The perceived dependency of patients, with reduced awareness of the benefits of mobility are proposed as risk factors for the health care professional's reduced support with patient mobility within hospitals (Brown et al. 2004; Fisher et al. 2011). However there needs to be improved understanding of the reasons that mobility is not sufficiently encouraged in the hospitalised patient with Parkinson's disease. 


\section{Clarity of direction of care}

A recurring theme in the data is uncertainty and poor clarity regarding the role of the physiotherapist within the overall aims of care. The participants encounter particular difficulties knowing what their role encompasses when a patient's swallow has deteriorated to the point that aspiration is inevitable:

'where are we going with this person because you know they're going to develop another chest infection because we've already said their swallow is inadequate...and so it's difficult to know sometimes when to stop.' (P003; focus group)

The struggle of knowing when to withdraw treatment appears entwined with a perceived ambiguity in the value of prescribing antibiotics when a patient is accepting the risk of aspiration. The clarity of the aims of care is perceived as lost and the participants experience frustration with the medical team not understanding their concerns. Ultimately, participants are driven by a fear of prolonging patient suffering with a feeling of being trapped between the duty to alleviate suffering and the role of medicine to cure:

'It's that balance... this is a matter of time...I'm just prolonging the inevitable.' (P001; focus group)

Some of these concerns stem from the challenge and discomfort in determining a patients understanding of a situation and their wishes when they are acutely unwell and possibly experiencing cognitive decline:

'it was quite difficult to make sure that the patient has consent because communication was a problem as well, so trying to establish that the patient understood' (P001; focus group) 
The experience of participants is that they are unsure if a patient wants to receive treatment they are offered. It is possible that with the right education for patients, improved understanding of a patient's wishes and use of advanced directives may resolve some of the ambiguity health care professional's face when a patient is critically unwell and unable to express themselves.

\section{Strengths and limitations of this study}

The strength of this research culminates in the potential significance of the findings in contributing to an area of patient care that is currently neglected in the evidence base. While generalisability is a concern often raised about qualitative research (Myers, 2000) this exploratory study is not seeking to be generalisable, instead hoping that health care professional's may find resonance with the emerging themes (John, 2009), forming a cog in a wheel that is helping drive forward the improvement of care for those with Parkinson's disease.

The data from diary entries provided an opportunity for greater depth of understanding, for a phenomena experienced infrequently, however a weakness of this study is that the three months of data collection provided limited opportunity to record these lived experiences and thus prolonged data collection may have increased the credibility of findings (Lincoln and Guba, 1985). Furthermore, whilst providing very open instructions for the diary was felt to be essential in such an exploratory study, a model of reflection may have helped to provide a structure for participants, encouraging greater depth of exploration of their experiences (Bedwell et al. 2012). 
There is recognition that the subjective nature of IPA renders it impossible for the researcher to completely remove themselves from their understanding, as well as recognition that new understanding is an interpretive construction of both participant and researcher (Larkin et al 2006). The researcher's background as a physiotherapist with twelve years' experience, presents the close relationship to the study. Within the IPA literature, it is intently debated how trustworthiness is 'dependent on, and complicated by, the researcher's own conceptions' (Smith, 1996 :264) and that this could also be seen as a strength of the methodology in reflecting the essential truth and reality of the human world (Ashworth, 1997).

In this case, it is felt that preconceptions support the 'fusion of horizons' which serves to enrich understanding (Ashworth, 1997: 222), particularly important in an exploratory study. The researcher kept a diary during the research process in which pre-existing beliefs and assumptions were recognised, demonstrating the intent to support credibility, dependability, transferability and confirmability of the processes used and the results gained (Lincoln and Guba, 1985).

\section{Conclusions}

People with Parkinson's disease are at significant risk of developing respiratory compromise towards the end of life. These professional participants describe exposure to the distressing and complex presentation of a condition that renders patients increasingly dependent on others, yet potentially vulnerable in the hands of medical advancement. Participants outline the need for more education and knowledge for both patients and health care professional's. 
Questions remain regarding the value of proactively anticipating decline in the face of uncertainty associated with treatment options and end of life decisions.

Future research should widely examine perceptions and experiences of larger numbers of physiotherapists alongside other health care professional's, to see if similar themes exist and build greater depth of understanding. Secondly, further research is required to consider the effectiveness of physiotherapy secretion clearance techniques in those with Parkinson's disease. Finally, there would appear to be considerable value investigating the lived experiences of people with Parkinson's disease admitted to hospital.

\section{Acknowledgements}

My supervisor, my colleagues and the physiotherapists who participated in this study, for their openness and honesty when discussing their experiences.

Declaration of interest's statement

The authors report no conflicts of interest.

\section{REFERENCE LIST}

All-Party Parliamentary Group on Parkinson's. (2009) Please mind the gap: Parkinson's disease services today. Available at: http://www.parkinsons.org.uk/content/inquiry-access-healthand-social-care (Accessed: 18 April 2015).

Anderson, J. L., Hasney, K. M. and Beaumont, N. E. (2005) 'Systematic review of techniques to enhance peak cough flow and maintain vital capacity in neuromuscular disease: the case for mechanical insufflation-exsufflation', Phys Ther rev, 10 (1), pp. 25-33.

Ashburn, A., Jones, D., Plant, R., Lovgreen, B., Kinnear, E., Handford, F., Loader, S. (2004) 'Physiotherapy for People with Parkinson's in the UK: an exploration of practice', Int J Ther Rehabil, 11(4), pp. 160-166. 
Ashworth, P. D. (1997) 'The variety of qualitative research. Part two: non-positivist approaches', Nurse Educ Today', 17 (3) pp. 219-224.

Bedwell, C., McGowan, L. and Lavender, T. (2012) 'Using diaries to explore midwives' experiences in intrapartum care: an evaluation of the method in a phenomenological study', Midwifery, 28 (2), pp. 150-155.

Berry, J. K., Vitalo, C. A., Larsen, J. L., Patel, M., Kim, M. J. (1996) 'Respiratory Muscle Strength in Older Adults', Nursing Research, 45(3), pp. 154-159.

BMJ Group and The Royal Pharmaceutical Society of Great Britain (2015) British National Formulary. Available at: https://www.medicinescomplete.com/mc/bnf/current/index.htm (Accessed: 18 April 2015).

Bradbury-Jones, C., Irvine, F. and Sambrook, S. (2010) 'Phenomenology and participant feedback: convention or contention', Nurse Res, 17(2), pp. 25-33.

Bramley, N. and Eatough, V. (2005) 'The experience of living with Parkinson's disease: An interpretative phenomenological analysis case study', Psychology and Health, 20(2), pp. 223225.

Brown, C. J., Friedkin, R. J. and Inouye, S. K. (2004) 'Prevalence and Outcomes of Low Mobility in Hospitalized Older Patients', Am Geriatr Soc, 52(8), pp. 1263-1270.

Clisset, P., Porock, D., Harwod, R. H. and Gladman, J. R. F. (2013) 'The challenges of achieving person-centred care in acute hospitals: A qualitative study of people with dementia and their families,' Int J Nurs Stud, 50 (11), pp. 1495-1503.

Department of Health (2001) National Service Framework for Older People [Online]. Available at: https://www.gov.uk/government/publications/quality-standards-for-care-services-forolder-people (Accessed: 19 April 2018).

Department of Health (2009) Reference guide to consent for examination or treatment. [Online]. Available at: https://www.gov.uk/government/publications/reference-guide-toconsent-for-examination-or-treatment-second-edition (Accessed 11 April 2018).

Dowding, A. H., Shenton, C. L. and Salek, S. S. (2006) 'A Review of the Health-Related Quality of Life and Economic Impact of Parkinson's Disease', Drugs Aging, 23(9), pp. 693-721.

Ebihara, S., Saito, H., Kanda, A., Nakajoh, M., Takahashi, H., Arai, H., Saskai, H. (2003) 'Impaired Efficacy of Cough in Patients with Parkinsons Disease', Chest, 124(3), pp. 10091015.

Eliot and Associates, (2005) Guidelines for conducting a focus group. [Online]. Available at: https://datainnovationproject.org/wpcontent/uploads/2017/04/4_How_to_Conduct_a_Focus_Group-2-1.pdf (Accessed: 10 January 2018). 
Entwistle, V. A., Carter, S.M., Cribb, A., McCaffert, K. (2010) 'Supporting Patient Autonomy: The Importance of Clinician-patient Relationships', JGIM, 25(7), pp. 741-745.

Fisher, S.R., Graham, J.E., Brown, C.J., Galloway, R. V., Ottenbacher, K. J., Allman, R .M., Ostir, G.V. (2011) 'Factors that differentiate level of ambulation in hospitalised older adults', Age Aging, 41(1), pp. 107-111.

Fontana, G. A. and Lavorini, F. (2006) 'Cough Motor Mechanisms', Respir Physiol Neurobiol, 152 (3), pp. 266-281.

Francis, R. (2013) The Mid Staffordshire NHS Foundation Trust Public Enquiry [Online]. Available at: http://www.midstaffspublicinquiry.com/report (Accessed: 11 April 2015).

Griffiths, J. (2014) Health care cost savings - proactive prevention or reactive treatment. Washington: Nutrition.

Hanson, E. C. (2006) Successful Qualitative Health Research. Maidenhead: Open University Press.

Inzelberg, R., Peleg, N., Nisipeanu, P., Magadle, R., Carasso, R L., Weiner, P. (2005) ‘Inspiratory Muscle Training and the Perception of Dyspnea in Parkinson's Disease', The Can J Neurol Sci, 32(2), pp. 213-217.

John, H., Hale, E. D., Treharne, G. J., Carroll, D., Kitas, G. D. (2009). 'All singing from the same hymn sheet': Healthcare professional's perceptions of developing patient education material about the cardiovascular aspects of rheumatoid arthritis', Musculoskeletal Care, 7(4), pp. 256271.

Jones, S. L. and Hindle, J. V. (2011) 'Parkinson's disease in the acute hospital', Clin Med, 11(1), pp. 84-8.

Jones, U., Enright, S. and Busse, M. (2012) 'Management of respiratory problems in people with neurodegenerative conditions: a narrative review', Physiother, 98 (1), pp. 1-12.

Kalf, J. G., De Swart, B. J. M., Bloem, B. R. and Munneke, M. (2012) 'Prevalence of oropharyngeal dysphagia in Parkinsons disease: a meta analysis', Parkinsonism Relat Disord, 18 (4), pp. 311-315

Keus, S., Munneke, M., Graziano, M., Paltamaa, J., Pelosin, E., Domingos, J., Bruhlmann, S., Ramaswamy, B., Struiksma, C., Rochester, L., Nieuwboer, A., Bloem, B. (2014) European Physiotherapy Guideline for Parkinson's disease, [Online]. Available at: http://parkinsonnet.info/news/review-version-of-new-european-guideline-for-pd-nowavailable! (Accessed: 19 April 2015).

Koseoglu, F., Inan, L., Ozel, S., Deviren, S. D., Karabiyikoglu, G., Yorgancioglu, R., Atasoy, T., Ozturk, A. (1997) 'The effects of a pulmonary rehabilitation program on pulmonary function 
tests and exercise tolerance in patients with Parkinson's disease', Funct Neurol, 12 (6), pp. 319-325.

Larkin, M., Watts, S. and Clifton, E. (2006) 'Giving voice and making sense in Interpretative Phenomenological Analysis', Qualitative Research in Psychology, 3 (2), pp. 102-120

Larsson, I., Liljedahl, K. and Gard, G. (2010) 'Physiotherapists' experience of client participation in physiotherapy interventions: A Phenomenographic study', Adv Physiother, 12 (4), pp. 217-223.

Lee, k. and Sheppard, L. (1998) 'An investigation into medical students' knowledge and perceptions of Physiotherapy services', Aust J Physiother, 44(4), pp. 239-245.

Leibson, C. L., Long, K. H., Maraganore, D. M., Bower, J. H., Ransom, J. E., O'Brien, P. C., Rocca, W. A. (2006a) 'Direct Medical Costs Associated With Parkinson's Disease: A Population-Based Study', Mov Disord, 21(11), pp. 1864-1871.

Leibson, C, L., Maraganore, D. M., Bower, J. H., Ransom, J. E., O'Brien, P. C., Rocca, W. A. (2006b) 'Comorbid conditions associated with Parkinson's Disease: A Population Based Study', Mov Disord, 21(4), pp. 446-455.

Low, V., Ben-Shlomo, Y., Coward, E., Fletcher, S., Walker, Richard., Clarke, CE. (2015) 'Measuring the burden and mortality of hospitalisation in Parkinson's disease: A crosssectional analysis of the English Hospital Episodes Statistics database 2009-2013', Parkinsonism Relat. Disord, 21(5), pp. 449-454.

Lincoln, Y. S. and Guba, E. G. (1985) Naturalistic Inquiry. Thousand Oaks. USA: SAGE Publications.

Myers, M. (2000) 'Qualitative Research and the Generalizability Question: Standing Firm with Proteus', Qual Rep, 4(3/4).

NHS Employers (2014) Avoiding unplanned admissions enhanced service: proactive case finding and care review for vulnerable people. Guidance and audit requirements. [Online] Available at: http://www.nhsemployers.org/your-workforce/primary-care-contacts/generalmedical-services/enhanced-services/enhanced-services-201415

(Accessed: 11 April 2018).

National Institute for Health and Care Excellence (2012) Patient experience in adult NHS Services: Improving the experience of care for people using adult health services. [Online] Available at: http://www.nice.org.uk/guidance/cg138 (Accessed: 11 April 2018).

National Institute for Health and Care Excellence. 2016a. Motor neurone disease: The use of non-invasive ventilation in the management of motor neurone disease.

https://www.nice.org.uk/guidance/NG42 (accessed 25 April 2018)

National Institute for Health and Care Excellence. 2016b. Palliative care - secretions. https://cks.nice.org.uk/palliative-caresecretions\#!scenario:1 (accessed 25 April 2018) 
National Institute for Health and Care Excellence (2017) Parkinson's disease in adults [Online] Available at: https://www.nice.org.uk/guidance/ng71/resources/parkinsons-disease-inadults-pdf-1837629189061 (Accessed: 10 January 2018).

Pal, P. K., Sathyaprabha, T. N., Tuhina, P., and Kandavel. T (2007) 'Pattern of subclinical pulmonary dysfunction in Parkinson's disease and the effect of levodopa', Mov Disord, 22(3), pp. 420-4.

Parkinson's UK (2015) Parkinson's UK Get it on time campaign. Available at: http://www.parkinsons.org.uk/content/get-it-time-campaign (Accessed: 9 April 2018).

Pinter, B., Diem-Zangerl, A., Wenning, GK., Scherfler, C., Oberaigner, W., Seppi, K., Poewe, W. (2015) 'Mortality in Parkinson's Disease: a 38year follow-up study', Mov Disord, 30 (2) pp. 266-269

Pitts, T., Bolser, D., Rosenbek, J., Troche, M., Okun, M. S., Sapienza, C. (2009) 'Impact of Expiratory Muscle Strength Training on Voluntary Cough and Swallow Function in Parkinson Disease', Chest, 135 (5), pp. 1301-1309.

Postuma, R., Berg, D., Adler C., et al (2016) 'The new definition and diagnostic criteria of Parkinson's disease', Lancet, 15 (6), pp. 546-548.

Reese, S. L. (2007) ‘Psychological Factors in Parkinson's Disease', Dis Mon, 53 (5), pp. 291-295.

Riley, AM. (2017) 'Our \#EndPJParalysis Journey'. Available at: http://improvement.nhs.uk/resources/our-endpjparalysis-journey/ (Accessed: 23 April 2017)

Sabate, M., Gonzalez, I., Ruperez, F. and Rodriguez, M. (1996) 'Obstructive and restrictive pulmonary dysfunctions in Parkinson's Disease', J Neurol Sci, 138 (1-2), pp. 114-119.

Sathyaprabha, T. N., Kapavarapu, P. K., Pal, P. K., Thennarasu, K., Raju, T. R. (2005) ‘Pulmonary Functions in Parkinson's Disease', Indian J Chest Dis Allied Sci, 47 (4), pp. 251-257.

Schrag, A., Ben-Shlomo, Y. and Quinn, N. (2002) 'How common are complications of Parkinson's Disease?' J Neurol, 249 (4), pp. 419-423.

Smith, J. A. (1996) 'Beyond the divide between cognition and discourse: using Interpretative Phenomenological Analysis in Health Psychology', Psychology and Health, 11 (2), pp. 261-271.

Smith, J. A., Flowers, P. and Larkin, M. (2009) Interpretative Phenomenological Analysis: Theory, Method and Research. London: SAGE Publications.

The Health Foundation. (2015) Person Centred Care. Available at: http://www.health.org.uk/areas-of-work/topics/person-centred-care/person-centred-care/ (Accessed: 3 April 2018). 
The Kings Fund (2010) Avoiding hospital admissions: Lessons from evidence and experience. [Online] Available at: http://www.kingsfund.org.uk/publications/avoidinghospitaladmissions

(Accessed: 4 April 2018).

The Kings Fund (2014) Making our health and care systems fit for an ageing population. [Online] Available at: http://www.kingsfund.org.uk/publications/making-our-health-andcare-systems-fit-ageing-population (Accessed: 11 April 2018).

Tomlinson, C. L., Patel, S., Meek, C., Herd, C. P., Clarke, C. E., Stowe, R., Shah, L., Sackley, C. M., Deane, K. H.O; Wheatley, K., Ives, N. (2012) 'Physiotherapy Intervention in Parkinson's Disease: Systematic Review and Meta-analysis', BMJ, 345, pp. 1-14.

Troche, M.S., Okun, M. S., Rosenbek, J. C., Musson, N., Fernandez, H. H., Rodriguez, R., Romrell, J., Pitts, T., Wheeler-Hegland, K. M., Sapienza, C. M. (2010) 'Aspiration and swallowing in Parkinson disease and rehabilitation with EMST', Neurol, 75 (21), pp. 19121919.

Van der Marck, M. A., Kalf, J. G., Sturkenboom, I.H.W.M., Nikkrake, M. J., Munneke, M. (2009) 'Multidisciplinary care for patients with Parkinson's disease', Parkinsonism Relat Disord, 15 (suppl.13) pp. S219-S223.

Webb, C. (2003) 'Editors Note: Introduction to guidelines on reporting qualitative research', Journal of Advanced Nursing, 42(6), pp. 544-545.

Wiart, L. and Burwash, S. (2007) 'Qualitative Research Is Evidence, too', Aust J Physiother, 53 (4), pp. 215-216.

Wilkinson, J. (1997) 'Developing a concept analysis of autonomy in nursing practice', Br J Nurs, 6(12), pp. 703-707.

Williamson, C., Simpson, J. and Murray, C. D. (2008) 'Caregivers' experiences of caring for a husband with Parkinson's disease and psychotic symptoms', Soc Sci Med, 67 (4), pp. 583-589. 